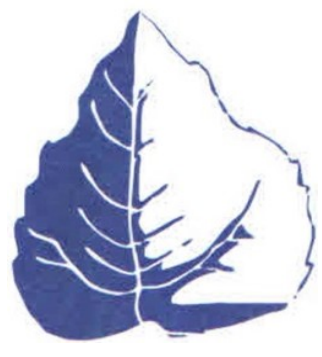

УДК 504.7

\section{ЭКОЛОГИЯ (ПО ОТРАСЛЯМ) ECOLOGY (ITS BRUNCHES)}

Парниковый эффект и его воздействие на окружающую среду Щербань А. В.

Каменский технологический институт (филиал) ЮРГПУ (НПИ) имени М. И. Платова (г. Каменск-Шахтинский, Российская Федерация)

Накопление в атмосфере так называемых парниковых газов (ПГ), в частности $\mathrm{CO}_{2}$, оказывает неблагоприятное воздействие на глобальный климат. В настоящей статье рассматриваются текущие ожидания в отношении физических и биологических эффектов, их потенциальных издержек для общества и вероятных издержек борьбы с выбросами. При наихудшем сценарии невозможно оценить с экономической точки зрения весь спектр возможных нелинейных синергетических эффектов. Однако в наиболее благоприятном случае представляется вероятным, что последствия находятся в пределах приемлемого диапазона, по крайней мере, в промышленно развитых странах мира. В странах третьего мира понятие доступности имеет сомнительную актуальность, что делает решение проблемы количественной оценки практически невозможным.

Ключевые слова: парниковые газы, атмосфера, выбросы соединений, глобальное потепление, химический состав, парниковый эффект.

Для цитирования: Щербань, А. В. Парниковый эффект и его воздействие на окружающую среду / А. В. Щербань // Экономика и экология территориальных образований. — 2021 . — Т. 5, № 2. — С. 59 65, https://doi.org/10.23947/2413-1474-2021-5-2-59-65

\title{
The greenhouse effect and its impacts on environment
}

A. V. Scherban'

Kamensk technological institute (affiliation) SRSPU (NPI) named after M.I. Platov (Kamensk-Shakhtinskiy, Russian Federation)

The buildup of so-called «greenhouse gases» in the atmosphere - $\mathrm{CO}_{2}$ in particular-appears to be having an adverse impact on the global climate. This article briefly reviews current expectations with regard to physical and biological effects, their potential costs to society, and likely costs of abatement. For a «worst case» scenario it is impossible to assess, in economic terms, the full range of possible non-linear synergistic effects. In the «most favorable» case, however, it seems likely that the impacts are within the «affordable» range, at least in the industrialized countries of the world. In the «third world» the notion of affordability is of doubtful relevance, making the problem of quantitative evaluation almost impossible.

Keywords: greenhouse gases, atmosphere, emissions of compounds, global warming, chemical composition, greenhouse effect.

For citation: A. V. Scherban'. The greenhouse effect and its impacts on environment. Economy and ecology of territorial formations, 2021, vol. 5, no 2, pp. 59-65. https://doi.org/10.23947/2413-1474-2021-5-2-59-65 
Введение. Климатологи считают, что повышение концентрации в атмосфере углекислого и других парниковых газов, выделяемых в результате деятельности человека, такой как сжигание ископаемого топлива и вырубка лесов, согревает Землю. Механизм, широко известный как парниковый эффект - это то, что делает Землю пригодной для жизни. Эти газы в атмосфере действуют как стекло теплицы, впуская солнечный свет и предотвращая утечку тепла. Но человеческая деятельность изменила химический состав атмосферы за счет накопления парниковых газов - в первую очередь углекислого газа, метана и окиси азота [1-2].

Повышение температуры окружающей среды и изменения, произошедшие в связи с этим процессом, напрямую связаны с увеличением антропогенных выбросов парниковых газов в атмосферу. Повышение температуры, как утверждалось, вызвано в основном выбросом соединений на основе углерода из ископаемого топлива, потребляемого для производства электроэнергии. Известно, что концентрации углекислого газа, метана и азота растут и в последние годы их парниковые газы, главным образом хлорфторуглероды (ХФУ), были добавлены в атмосферу в значительных количествах [1].

Цель исследования автора - изучение чистого парникового эффекта сельскохозяйственных систем на примерах последствий глобального потепления, разработка модельных алгоритмов на уровне фермерских хозяйств для снижения выбросов в атмосферу $\mathrm{CO}_{2}, \mathrm{CH}_{4}$ и $\mathrm{N}_{2} \mathrm{O}$.

История парниковых газов. Существование парникового эффекта было открыто Жозефом Фурье в 1824 году. Данный факт и доказательства были еще более закреплены Клодом Пуйе в 1827 и 1838 годах и обоснованы экспериментальными наблюдениями Джона Тиндаля в 1859 году. Этот эффект был полностью оценён Сванте Аррениусом в 1896 году. Однако термин «парниковый» не использовался для описания эффекта ни одним из этих ученых; впервые этот термин был использован Нильсом Густавом Экхольмом в 1901 году.

Выбросы $\mathbf{C H}_{4}$. Метан выделяется при добыче и транспортировке угля, природного газа и нефти. Выброс метана происходит также при разложении органических отходов в сельском хозяйстве, в твердых бытовых отходах, на свалках и при выращивании скота. Метаболические выбросы метана при содержании скота оценивались с учетом видов животных, производительности и кормления. На основе валовой энергии сырья выбросы метана оценивались с помощью коэффициентов пересчета. Для количественной оценки выделения метана из органических удобрений при хранении в качестве основы для расчета потенциала метанообразования был выбран выход экскрементов (количество, химические компоненты, разлагаемость), затем количество полученного метана определялось с учетом системы хранения [2-3].

Выбросы $\mathrm{N}_{2} \mathbf{O}$. Выбросы $\mathrm{N}_{2} \mathrm{O}$ оценивались в ходе сельскохозяйственной и промышленной деятельности, а также при сжигании твердых отходов и ископаемых видов топлива. Предполагалось, хотя и очень упрощенно, что $1,25 \%$ окиси азота, поступающего в почву при органическом и минеральном удобрении, фиксации $\mathrm{N}_{2}$ и осаждении $\mathrm{N}$, выделяется в виде $\mathrm{N}_{2} 0-\mathrm{N}$. В качестве альтернативы был применен коэффициент эмиссии $\mathrm{N}_{2} 0-\mathrm{N}$, равный $2,53 \%$ от общего ввода $\mathrm{N}$, как это было получено в ходе многочисленных измерений на экспериментальной ферме. Косвенные выбросы $\mathrm{N}_{2} 0$ от газообразных потерь $\mathrm{NH}_{3}$, а также от потерь $\mathrm{N}$ были количественно оценены с использованием коэффициента выбросов.

Углекислый газ $\left(\mathrm{CO}_{2}\right)$. Углекислый газ попадает в атмосферу при сжигании ископаемых видов топлива (уголь, природный газ и нефть), твердых отходов, деревьев и изделий из древесины, а также в результате определенных химических реакций (например, при производстве цемента). Углекислый газ удаляется из атмосферы (или секвестрируется), когда он поглощается растениями в рамках биологического углеродного цикла [3].

Источники парниковых газов. Наиболее распространенными парниковыми газами в атмосфере Земли являются:

- водяной пар $\left(\mathrm{H}_{2} \mathrm{O}\right)$;

- углекислый газ $\left(\mathrm{CO}_{2}\right)$;

- метан $\left(\mathrm{CH}_{4}\right)$; 
- окись азота $\left(\mathrm{N}_{2} 0\right)$;

- озон $\left(\mathrm{O}_{3}\right)$;

- хлорфторуглероды.

Атмосферные концентрации парниковых газов определяются балансом между источниками (выбросы газа в результате деятельности человека и природных систем) и поглотителями (удаление газа из атмосферы путем превращения в другое химическое соединение). Доля выбросов, остающихся в атмосфере после определенного времени, является воздушной фракцией (ВФ). Годовая ВФ - это отношение атмосферного прироста в данном году к общему объему выбросов в этом году. Доля $\mathrm{CO}_{2}$ в ВФ за последние 65 лет увеличивалась на $0,25 \pm 0,21 \%$ в год [4-5].

По процентному вкладу в парниковый эффект выделяют четыре основных газа: водяной пар 36-70\%, углекислый газ - 9-26\%, метан - 4-9\%, озон - 3-7\% (рис. 1). Физически нереально определить процент по каждому газу, поскольку полосы поглощения и излучения газов перекрываются (отсюда и диапазоны, приведенные выше).

При изучении чистого парникового эффекта сельскохозяйственных систем важное значение имеют не только выбросы $\mathrm{CO}_{2}$ и $\mathrm{CH}_{4}$, но и в силу их высокого удельного парникового потенциала выбросы $\mathrm{N}_{2} 0$. Для выбросов на уровне фермерских хозяйств были разработаны модельные подходы на основе частично упрощенных модельных алгоритмов. Чистый парниковый эффект сельскохозяйственных систем должен учитывать, помимо биологических потоков, также и технические потоки, то есть все выбросы $\mathrm{CO}_{2}$, связанные с использованием ископаемой энергии [4].

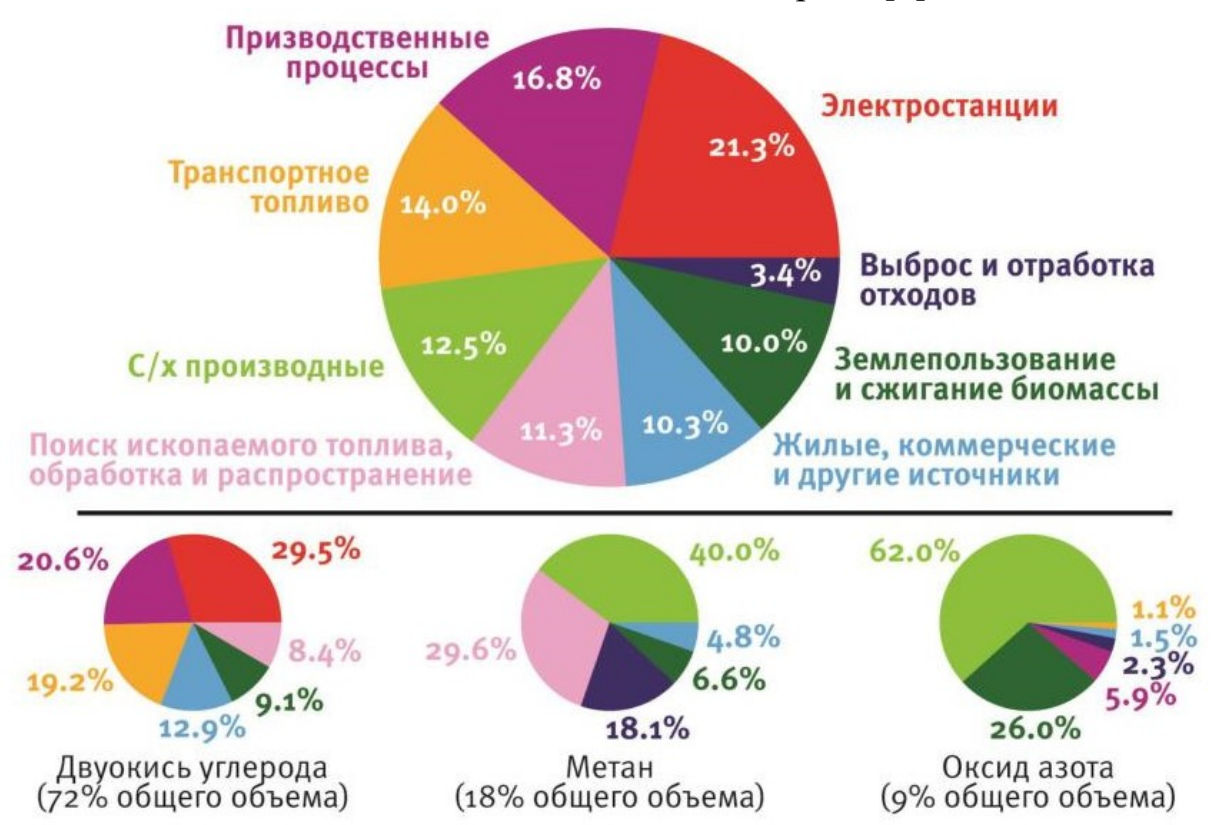

Рис. 1. Выбросы парниковых газов

Солнечная энергия достигает поверхности Земли, поверхность земли поглощает энергию и нагревается:

— теплая поверхность земли дает инфракрасное излучение, парниковые газы поглощают его, выходя с поверхности;

- газы заряжаются энергией, а затем дают больше излучения;

— часть этого излучения возвращается на поверхность земли, еще больше нагревая ее, этот процесс мы называем «парниковым эффектом» (рис. 2). 


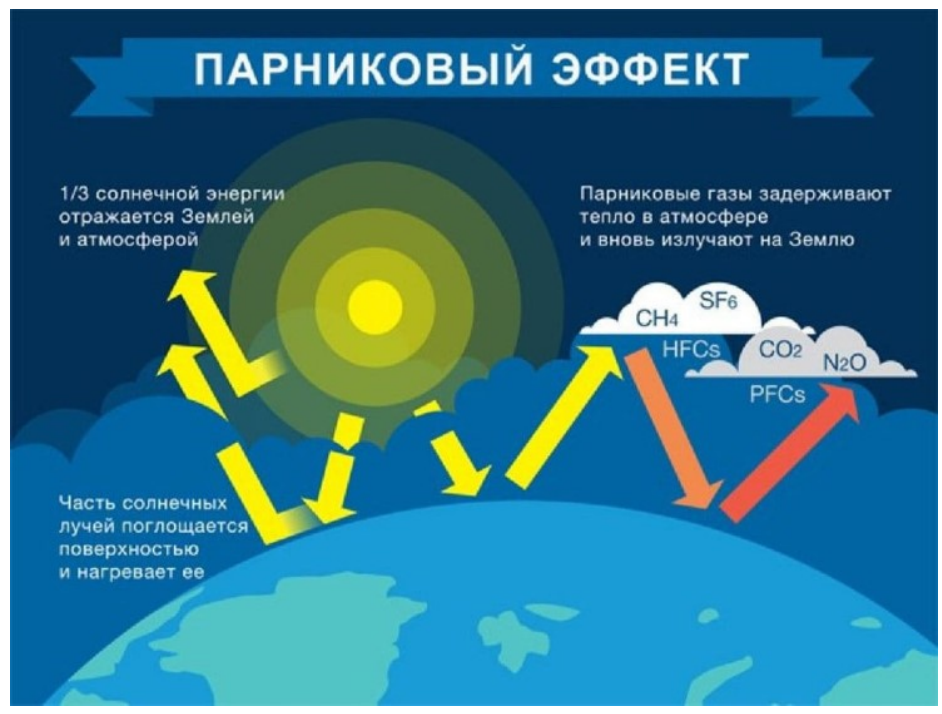

Рис. 2. Парниковый эффект

Воздействие парникового эффекта на окружающую среду. Глобальное потепление. Увеличение концентрации парниковых газов вызывает уменьшение исходящего инфракрасного излучения, поэтому климат Земли должен каким-то образом измениться, чтобы восстановить баланс между входящим и исходящим излучением. Это изменение климата будет включать в себя глобальное потепление земной поверхности и нижней атмосферы, поскольку потепление является самым простым способом для климата избавиться от лишней энергии. Однако небольшое повышение температуры вызовет множество других изменений, например, облачного покрова и характера ветра. Некоторые из этих изменений могут усиливать потепление (положительные обратные связи), другие - противодействовать ему (отрицательные обратные связи). Используя сложные климатические модели, межправительственная группа экспертов по изменению климата предсказала, что глобальная средняя температура поверхности повысится на $1,4^{\circ} \mathrm{C}-$ до $5,8^{\circ} \mathrm{C}$ к концу 2100 года. Эта проекция учитывает воздействие аэрозолей, которые имеют тенденцию охлаждать климат, а также замедляющее воздействие океанов, обладающих большой тепловой мощностью. Однако существует много неопределенностей, связанных с этим прогнозом, таких как будущие темпы выбросов парниковых газов, климатические обратные связи и размер задержки океана [1-3].

Повышение уровня моря. Если произойдет глобальное потепление, уровень моря поднимется из-за двух различных процессов. Во-первых, более высокая температура вызывает повышение уровня моря из-за теплового расширения морской воды. Во-вторых, тающие ледники и ледяные щиты Гренландии и Антарктиды также добавят воды в океан. Прогнозируется, что средний уровень моря на Земле поднимется на 0,09-0,88 м с 1990 по 2100 год.

\section{Потенциальное воздействие на жизнь человека:}

1) экономический эффект. Более половины населения Земли живет в пределах 100 километров от моря. Большая часть этого населения живет в городах, которые являются морскими портами. Измеримое повышение уровня моря будет иметь серьезные экономические последствия для низменных прибрежных районов и островов, например, произойдет увеличение темпов эрозии пляжей вдоль береговых линий, вытеснение пресных грунтовых вод на значительное расстояние вглубь страны;

2) сельское хозяйство. Эксперименты показали, что при более высоких концентрациях $\mathrm{CO}_{2}$ растения могут расти быстрее. Однако глобальное потепление может повлиять на атмосферу и изменить глобальную структуру осадков, а также содержание влаги в почве на различных континентах. Поскольку неясно, как глобальное потепление повлияет на климат в региональном или местном масштабе, вероятные последствия для биосферы остаются неопределенными; 
3) воздействие на водные системы. Потеря прибрежных водно-болотных угодий, безусловно, может привести к сокращению популяции рыб, особенно моллюсков. Увеличение солености в эстуариях уменьшит количество пресноводных видов, но может увеличить присутствие морских. Однако полное воздействие на морские виды неизвестно;

4) влияние на гидрологический цикл. Глобальные осадки, вероятно, увеличатся. Однако неизвестно, как изменится их региональная структура. В некоторых регионах осадков выпадает больше, а в других - меньше. Кроме того, более высокие температуры увеличат испарение. Эти изменения создадут новые стрессы для многих систем управления водными ресурсами.

Меры по сокращению выбросов парниковых газов и по борьбе с ними. Сокращение выбросов парниковых газов имеет центральное значение для всех стран, поскольку основная тяжесть этой проблемы носит глобальный характер, и ни одна страна или группа стран не могут обеспечить свое собственное решение. Вот почему международное и региональное сотрудничество более востребовано и широко пропагандируется в рамках глобального атмосферного здравомыслия. В связи с этой борьбой недавно вступила в силу Рамочная конвенция Организации Объединенных Наций об изменении климата, направленная на решение глобальной климатической проблемы. Это было сделано в форме международного соглашения разных страны из различных регионов, чтобы снизить опасную концентрацию антропогенных ПГ в атмосфере [6].

Механизм чистого развития (МЧР) предполагает массовое внедрение технологий возобновляемых источников энергии (ВИЭ) для производства электроэнергии и секвестрации углекислого газа. Помимо снижения выбросов парниковых газов в результате использования возобновляемых источников энергии, становится реальностью энергетическая безопасность. Механизм чистого развития является основополагающей идеей Киотского протокола под эгидой Рамочной конвенции Организации Объединенных Наций об изменении климата (РК ООН). Развивающиеся страны более активно участвуют в развитии возобновляемых источников энергии. В 2009 году на их долю приходилось 53\% мирового производства электроэнергии на основе ВИЭ. Первоначальная идея создания МЧР заключалась в стратегическом снижении уровня выбросов в результате производства и потребления энергии до устойчивой интенсивности. Однако предполагалось, что механизмы сокращения выбросов будут финансироваться промышленно развитыми странами, в результате чего средства фонда будут предоставляться развивающимся странам в качестве спонсорской помощи для программ использования возобновляемых источников энергии. Положительный результат внедрения еще предстоит увидеть, рост глобальных темпов использования возобновляемых источников энергии не соответствует реалистичному и ожидаемому уровню [7].

Заключение. Данное исследование показало, что деятельность, связанная с производством электроэнергии и ее потреблением, ассоциируется с выбросами, потенциально влияющими на парниковый газ, который является основным источником надвигающегося глобального потепления. На самом деле антропогенные выбросы парниковых газов от энергетической деятельности больше, чем выбросы парниковых газов от других видов человеческой деятельности. Исследование также показало необходимость сокращения выбросов парниковых газов, увеличения потребления возобновляемых источников энергии, чтобы решить вопросы энергетической безопасности, энергетического контроля и проблем, связанных со здоровьем.

Теплица строится из любого материала, пропускающего солнечный свет, обычно из стекла или пластика. Материал в основном нагревается, потому что солнце нагревает землю и содержимое теплицы, которое затем нагревает воздух в ней. Воздух продолжает нагреваться, потому что он ограничен размерами теплицы, в отличие от окружающей среды, где теплый воздух у поверхности земли поднимается и смешивается с более холодным воздухом наверху. Это можно продемонстрировать, открыв небольшое окошко возле крыши теплицы: температура в помещении значительно упадет. Это было доказано экспериментально. Таким образом, можно сделать вывод, что теплицы работают в первую очередь за счет предотвращения конвективного охлаждения. 
Более поздние количественные исследования доказали, что эффект инфракрасного радиоактивного охлаждения не является пренебрежимо малым и может иметь экономические последствия в отапливаемой теплице. Анализ вопросов ближнего инфракрасного излучения в теплице с экранами высокого коэффициента отражения показал, что установка таких экранов снижает теплопотребность примерно на 8\%, поэтому было предложено применение красителей на прозрачных поверхностях теплицы. Композитное, менее отражающее стекло или менее эффективное, но более дешевое простое стекло с антибликовым покрытием также давали экономию.

\section{Библиографический список}

1. Бринкман, Э. Физические проблемы экологии ; учебное пособие / Э. Бринкман ; пер. с англ. А. Д. Калашникова ; доп. В. В. Тетельмина. - Долгопрудный : Интеллект, 2012. — 287 с.

2. Современные глобальные изменения природной среды ; в 2 т. Т. 4 : Факторы глобальных изменений. - Москва : Научный мир, 2012. - 539 с.

3. Устойчивое развитие: экологические проблемы : сборник материалов IV региональной научно-практической конференции. - Брест, 2012. — 90 с.

4. Marco Aurelio dos Santosa, Luiz Pinguelli Rosaa, Bohdan Sikard,Elizabeth Sikarb, Ednaldo Oliveira dos Santosa (2006), «Gross greenhouse gas fluxes from hydro-power reservoir compared to thermopower plants», Energy Policy, 34, 481-488.

5. Bruce A. McCarl, Uwe A. Schneider «The Cost of Greenhouse Gas Mitigation in U.S.Agriculture and Forestry», Department of Agricultural Economics, Texas A\&M University, College Station, TX 77843 2124, USA. Center for Agricultural and Rural Development, Department of Economics, Iowa State University, Ames, IA, 50011-1070, USA.

6. Y.R.Dhumal, S.Chitode ,(5 May 2013), «Green House Automation using Zigbee and Smart Phone», International Journal of Advanced Research in Computer Science and Software Engineering 495-501.

7. John F. B. Mitchell, (February1989), THE «GREENHOUSE» EFFECT AND CLIMATE CHANGE», Reviews of Geophysics, 115-139.

Поступила в редакцию 01.02.2021

Запланирована в номер 25.03.2021

\section{Об авторе:}

Щербань Алексей Вадимович, студент Каменского технологического института (филиал) ЮРГПУ (НПИ) имени М. И. Платова (347801， РФ， г. Каменск-Шахтинский, ул. Сапрыгина, 6), scherban.aleksei@yandex.ru

\section{References}

1. Brinkman E. Fizicheskie problemy ekologii ; uchebnoe posobie [Physical problems of ecology; textbook translated from English by Kalashnikova A.D.] Dolgoprudny : Intelligence, 2012:287. (In Russ.)

2. Sovremennye global'nye izmeneniya prirodnoj sredy ; v 2 t. T. 4 : Faktory global'nyh izmenenij [Modern global changes in the natural environment ; in 2 vols. V. 4: Factors of global changes]. Moscow, Scientific world, 2012:539. (In Russ.)

3. Sovremennye global'nye izmeneniya prirodnoj sredy ; v 2 t. T. 4 : Faktory global'nyh izmenenij [Sustainable development: environmental challenges: collection of materials of the IV regional Scientific and practical conference]. Brest, 2012:90. (In Russ.)

4. Marco Aurelio dos Santosa, Luiz Pinguelli Rosaa, Bohdan Sikard,Elizabeth Sikarb, Ednaldo Oliveira dos Santosa (2006), «Gross greenhouse gas fluxes from hydro-power reservoir compared to thermopower plants», Energy Policy, 34:481-488.

5. Bruce A. McCarl, Uwe A. Schneider «The Cost of Greenhouse Gas Mitigation in U.S.Agriculture and Forestry», Department of Agricultural Economics, Texas A\&M University, College Station, TX 77843 - 
2124, USA. Center for Agricultural and Rural Development, Department of Economics, Iowa State University, Ames, IA, 50011-1070, USA.

6. Dhumal YR., Chitode S ,(5 May 2013), «Green House Automation using Zigbee and Smart Phone», International Journal of Advanced Research in Computer Science and Software Engineering: 495-501.

7. John F. B. Mitchell, (February 1989), the «greenhouse» effect and climate change», Reviews of Geophysics: $115-139$.

Received 01.02.2021

Scheduled in the issue 25.03.2021

\section{Author:}

Scherban' A.V. student,_Kamensk technological institute (affiliation) SRSPU (NPI) named after M.I. Platov (6, Saprigina, Kamensk-Shakhtinsk, RF, 347801), scherban.aleksei@yandex.ru 